\title{
Fabrication of Biosensor Based on Polyaniline/Gold Nanorod Composite
}

\author{
Uğur Tamer, Ali İhsan Seçkin, Erhan Temur, and Hilal Torul \\ Department of Analytical Chemistry, Faculty of Pharmacy, Gazi University, 06330 Ankara, Turkey \\ Correspondence should be addressed to Uğur Tamer, utamer@gazi.edu.tr
}

Received 15 February 2011; Accepted 22 March 2011

Academic Editor: Bengi Uslu

Copyright (C) 2011 Uğur Tamer et al. This is an open access article distributed under the Creative Commons Attribution License, which permits unrestricted use, distribution, and reproduction in any medium, provided the original work is properly cited.

\begin{abstract}
This present paper describes a new approach to fabricate a new amperometric sensor for the determination of glucose. Polyaniline (PANI) film doped with colloidal gold nanorod particles has been used to immobilize glucose oxidase by glutaraldehyde. The polyaniline/gold nanorod composite structure gave an excellent matrix for enzyme immobilization due to the large specific surface area and higher electroactivity. The composite has been characterized by cyclic voltammetry (CV), scanning electron microscopy (SEM), and surface-enhanced Raman spectroscopy (SERS). The SERS spectrum of the surface-immobilized glucose oxidase and the spectrum of the native enzyme indicate that the main feature of the native structure of glucose oxidase was conserved after being immobilized on the polymer matrix. The amperometric response was measured as a function of concentration of glucose at a potential of $0.6 \mathrm{~V}$ versus $\mathrm{Ag} / \mathrm{AgCl}$ in $0.1 \mathrm{M}$ phosphate buffer at $\mathrm{pH}$ 6.4. Linear range of the calibration curve was from $17.6 \mu \mathrm{M}$ to $1 \mathrm{mM}$ with a sensitivity of $13.8 \mu \mathrm{A} \cdot \mathrm{mM}^{-1} \cdot \mathrm{cm}^{-2}$ and a limit of detection (LOD) of $5.8 \mu \mathrm{M}$. The apparent Michaelis-Menten constant $K_{\mathrm{M}}$ was calculated as $1.0 \mathrm{mM}$ and the response time was less than 3 seconds.
\end{abstract}

\section{Introduction}

Quantitative determination of glucose has attracted wide interest for biomedical applications due to the high demand for blood glucose monitoring [1]. Numerous analytical techniques are available for glucose quantification especially those that are based on spectroscopy [2,3] and electrochemical sensing strategies [4]. The simplicity of electrochemical methods makes them highly attractive approaches for the detection of glucose [5]. Application of electrochemical methods at solid electrodes provides new approaches to the detection of glucose regarding controlling the surface properties of electrode so that to improve selectivity and sensitivity. For glucose monitoring, different strategies can be used to endow electrode surfaces with sensing abilities. As a new class of electrode materials, conducting polymers provide a suitable platform for the detection of biological analytes [6].

Conducting polymers have been proven to be suitable host matrices for dispersing metallic particles. Composites of conducting polymers and metal nanoparticles permit a facile flow of electronic charges across the polymer matrix during electrochemical processes. Conducting polymer plays an additional role in the electrochemical processes. In addition, metallic nanoparticles can also be dispersed well into the matrix of these polymers [7]. Gold nanoparticles have unique optoelectronic properties [8]. Therefore, through a suitable combination of conducting polymers and gold nanoparticles, newly modified surfaces can be generated with higher surface area and enhanced catalytical/electrocatalytic activities [9].

PANI has been of scientific and technological interest [10]. Different biomolecules such as enzymes, proteins, and DNA have been successfully immobilized on PANI modified electrodes and showed excellent performance [11, 12]. However, PANI has low electroactivities and conductivities in neutral solutions due to the slow electron transfer and diffusivities of proteins $[13,14]$. The electrochemical and electrocatalytic activities of PANI can be greatly increased if PANI is combined with gold nanoparticles [15]. For example, gold nanoparticles, functionalized with a sulfonate group, were incorporated into a polyaniline film by electropolymerization, and the resulting film was used for bioelectrocatalysis [16]. Spherical gold nanoparticles have 
also been adsorbed onto the surface of core-shell structured polystyrene/polyaniline, resulting in the formation of PS/PANI/Au nanocomposite, and glucose oxidase was entrapped into the nanocomposite-modified glassy carbon electrode [17]. A large surface area of PANI nanofiber was prepared using $\mathrm{HAuCl}_{4}$ as an oxidizing agent to immobilize glucose oxidase, and a glucose biosensor was developed [18]. This paper did not show any evidence as to what type of gold nanoparticle exists in the polymer matrix. To the best of our knowledge, there is only one report on using the colloidal gold nanorod particle which is embedded in the cellulose acetate membrane to fabricate the glucose biosensor [19]. Ren et al. worked with cellulose acetate to fabricate glucose biosensor, and they firstly compiled gold nanorod and GOx mixed solution on electrode surface after drying procedure. Then, enzyme was crosslinked by glutaraldehyde. At last point, the electrode was immersed into gold nanorodcellulose acetate mixture. In our study, firstly, PANI-gold nanorod polymer film was formed electrochemically on electrode surface. Then enzyme was crosslinked by glutaraldehyde as GOx.

In this present paper, we propose a new approach to fabricate a new amperometric sensor for the determination of glucose. PANI film doped with colloidal gold nanorod particles has been used to immobilize glucose oxidase by glutaraldehyde. The polyaniline/gold nanorod composite structure gave an excellent matrix for enzyme immobilization due to the large specific surface area and higher electroactivity. The detailed electrochemical investigation and spectroscopic characterization of film electrode were performed. The composite has been characterized by cyclic voltammetry $(\mathrm{CV})$, scanning electron microscopy (SEM), and surface enhanced Raman spectroscopy (SERS). For the determination of the optimum working conditions of the enzyme electrode, the effect of thickness of the polymeric film, $\mathrm{pH}$, and applied potential on the measured current values have been investigated. The stability of the enzyme electrode and the influence of possible interferences were also examined. The analytical performance of the obtained PANI/gold nanorod/enzyme electrodes with respect to linear range, reproducibility, response time, and stability is presented and discussed.

\section{Experimental}

2.1. Chemicals. Hydrogen tetrachloroaurate $\left(\mathrm{HAuCl}_{4}\right)$, hexadecyltrimetyl-ammonium bromide (CTAB), L-ascorbic acid (AA), and poly(sodium 4-styrenesulfonate) $25 \mathrm{wt} \%$ solution in water were obtained from Sigma-Aldrich (Taufkirchen, Germany). Silver nitrate $\left(\mathrm{AgNO}_{3}\right)$ and sodium borohydride $\left(\mathrm{NaBH}_{4}\right)$ were obtained from Merck (Darmstadt, Germany). Glutaraldehyde and glucose oxidase were purchased from Sigma and all the other chemicals were of analytical grades and were used as received. All solutions were prepared using deionized water, $18.2 \mathrm{M} \Omega \mathrm{cm}$ free from organic matter, which was obtained from a Millipore purification system and was deaerated with argon to remove the oxygen present.
2.2. Instrumentation. Electrochemical experiments were performed with a Gamry potentiostat (model Reference 600, USA). Polymer film formation was achieved in a conventional one-compartment three-electrode cell under argon atmosphere. SERS experiments were performed with a Delta $\mathrm{Nu}$ Examiner Raman Microscopy system with a $785 \mathrm{~nm}$ Laser source. A motorized microscope stage sample holder and a charge-coupled device (CCD) detector were used. Instrument parameters were as follows: 20x objective, $30 \mu \mathrm{m}$ spot size, 60 second acquisition time and baseline correction was performed for all measurements. Before SERS experiments, the fully reduced PANI/gold nanorod films were prepared by reducing the oxidized films in an aqueous solution containing $0.1 \mathrm{M} \mathrm{LiClO}_{4}$ at a constant cathodic potential of $0 \mathrm{~V}$ versus $\mathrm{Ag} / \mathrm{AgCl}$ until the current leveled off. The working electrode, a platinum disk $\left(0.022 \mathrm{~cm}^{2}\right)$, was cleaned by polishing with $\mathrm{Al}_{2} \mathrm{O}_{3}$ slurry for the cyclic voltammetric studies. The macrosamples of polymer films were prepared on a Pt macroelectrode $\left(1.0 \mathrm{~cm}^{2}\right)$ which was cleaned by holding it in a flame for a few minutes. All data points reported in this work represent the average of three replicates. All experiments were run at room temperature.

The morphologies of the films were examined by scanning electron microscopy (SEM). Scanning electron micrographs were obtained by a JSM-6400 electron microscope (JEOL), equipped with NORAN System 6 X-ray Microanalysis System and Semafore Digitizer.

2.3. Synthesis of Gold Nanorods and Surface Modification. Gold nanorods were prepared by the seed-mediated growth technique with slight modification [20]. The seed solution was prepared by mixing $7.5 \mathrm{~mL}$ of $0.1 \mathrm{M} \mathrm{CTAB}$ solution with $250 \mu \mathrm{L}$ of $0.01 \mathrm{M} \mathrm{HAuCl}_{4}$ solution. Once mixed, $600 \mu \mathrm{L}$ of $0.01 \mathrm{M}$ ice-cold $\mathrm{NaBH}_{4}$ was added to the resulting solution and allowed to stand for $5 \mathrm{~min}$ to form seed solution. To prepare rod-shaped gold nanoparticle, $4.75 \mathrm{~mL}$ of $0.1 \mathrm{M}$ CTAB, $1 \mathrm{~mL}$ of $0.01 \mathrm{M} \mathrm{HAuCl}_{4}$, and $60 \mu \mathrm{L}$ of $4 \times 10^{-3} \mathrm{M}$ $\mathrm{AgNO}_{3}$ were mixed, respectively. After that, $250 \mu \mathrm{L}$ of $0.1 \mathrm{M}$ ascorbic acid was added drop-wise to the resulting solution. Then, $5 \mu \mathrm{L}$ seed solution was added to the stock solution. This final mixture was stirred for 10 seconds and was allowed to stay for 3 hours at room temperature.

Before electropolymerization, the surface of gold nanorods was modified by poly(sodium 4-styrenesulfonate) (PSS) through electrostatic interaction between the positively charged surface of gold nanorod and the negatively charged PSS. Gold nanorod solution was centrifuged to remove any excess of CTAB from the surface of gold nanorod. The aqueous solution of PSS $(200 \mu \mathrm{L} 0.1 \mathrm{M})$ was added to $5 \mathrm{~mL}$ gold nanorod solution to form a mixture. After stirring for one hour in a sonicator, the precipitate was centrifuged and washed with deionized water and the procedure was repeated four times. The resulting particles were dispersed in a $5 \mathrm{~mL}$ electrochemical cell.

2.4. Fabrication of PANI-Gold Nanorod Electrode. In order to obtain a PANI/gold nanorod film, $0.1 \mathrm{M}$ aniline was added to $0.1 \mathrm{M}$ sulphuric acid and $0.1 \mathrm{M} \mathrm{Na}_{2} \mathrm{SO}_{4}$ aqueous solution 
containing $5 \mathrm{~mL}$ as synthesized PSS-CTAB-modified gold nanorod. The electropolymerization was carried out by applying seven potential cycles between -0.2 and $1.2 \mathrm{~V}$ versus $\mathrm{Ag} / \mathrm{AgCl}$. The obtained films were deposited onto platinum working electrodes by applying a program of successive voltammetric cycles. Following the synthesis process, the electrodes coated with the polymeric films were rinsed with water and were immersed in the background electrolyte.

Amperometric measurements were performed using a three-electrode cell consisting of PANI/nanorod working electrode, platinum wire counter electrode and $\mathrm{Ag} / \mathrm{AgCl}$ reference electrode. Measurements were conducted in a $5 \mathrm{~mL}$ $0.1 \mathrm{M}$ phosphate buffer at $\mathrm{pH}$ 6.4. A potential of $+0.6 \mathrm{~V}$ was applied to the electrochemical cell and solutions having different concentrations of glucose were added to the cell.

2.5. Immobilization of Glucose Oxidase on PANI-Gold Nanorod Electrode. Covalent coupling of glucose oxidase to the conducting polymer electrode was performed using glutaraldehyde in phosphate buffer solution with a $\mathrm{pH}$ of 7.4. For immobilizing the glucose oxidase enzyme, first $10 \mu \mathrm{L}$ of $0.1 \%$ glutaraldehyde were spread onto a PANI/gold nanorod film and was allowed to dry and to remove the unbound glutaraldehyde molecules, film electrode was again rinsed with deionized water. Then, the glucose oxidase was prepared by dissolving $3 \mathrm{mg}$ of glucose oxidase in $1 \mathrm{~mL}$ of $0.1 \mathrm{M}$ phosphate buffer and $30 \mu \mathrm{L}$ of this solution were added to the PANI/gold nanorod film electrode and kept for four hours. After that, PANI/gold nanorod film electrode was rinsed with deionized water to remove unreacted enzyme and was stored at $4^{\circ} \mathrm{C}$ when not in use.

\section{Results and Discussion}

3.1. Characterization of PANI/Gold Nanorod Electrode. Aqueous colloids of gold nanorods were synthesized through the reduction of chloroauric acid by means of ascorbic acid in the presence of the surfactant CTAB. Throughout the growth, CTAB forms micelles and a positively charged bilayer around the gold nanorods [21]. Figure 1 displays SEM images of the resulting gold nanorods. The obtained gold nanorods have uniform morphology with average diameter and length of $15 \mathrm{~nm}$ and $45 \mathrm{~nm}$, respectively (aspect ratio of 3). To immobilize the gold nanorods to the PANI film, the surface of gold nanorod particles is modified with PSS in order to form the negative charges. The presence of the negatively charged sulfonate-containing groups was proven by zeta potential measurements. Zeta potential values of CTAB modified gold nanorods and PSS-CTAB-modified gold nanorods were found to be $+0.46 \mathrm{mV}$ and $-2.92 \mathrm{mV}$, respectively. Negatively charged PSS-gold nanorod particles were introduced into polymer chain in the doping process of electrochemical polymerization.

Gold nanorod particles have good biocompatibility and the experimental results indicated that the enzyme electrode containing gold nanorods substantially enhances the response current. The increased electrocatalytic activity of

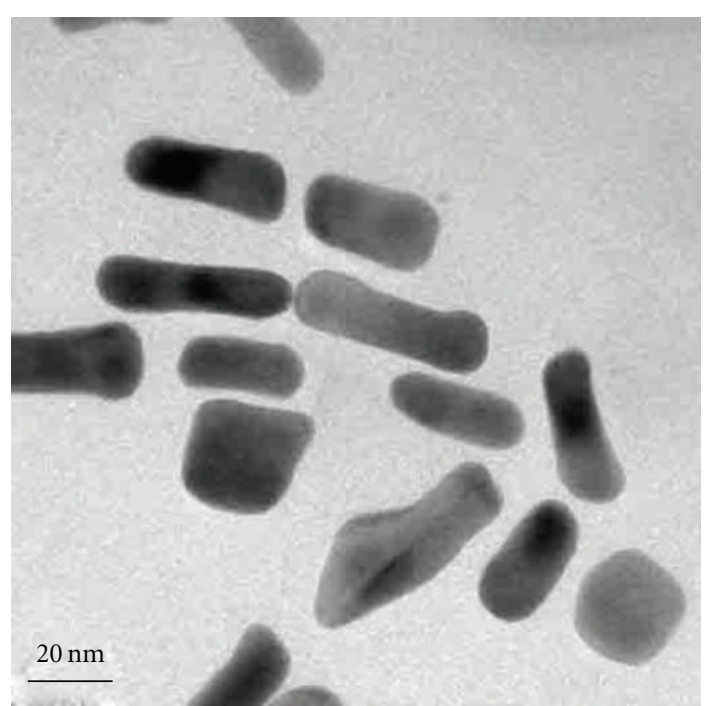

Figure 1: SEM image of gold nanorods.

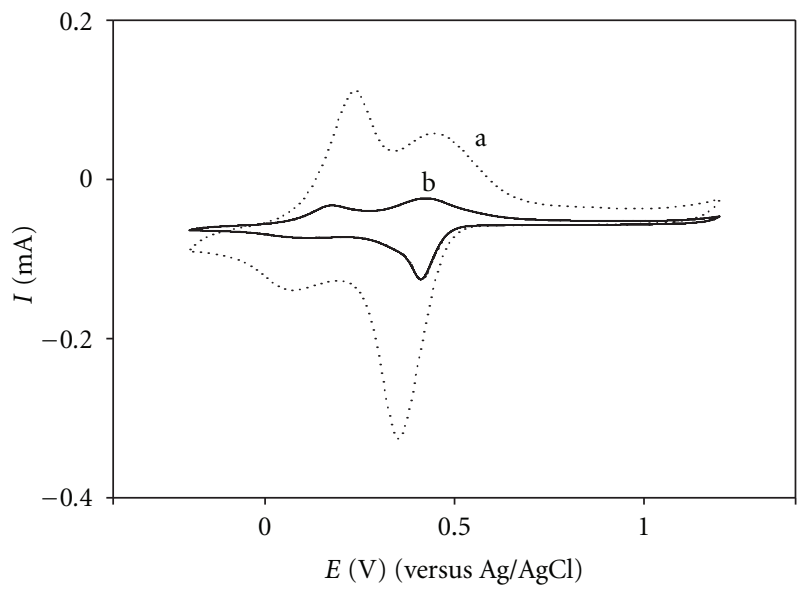

FIGURE 2: Cyclic voltammograms of (a) PANI/gold nanorod and (b) PANI film at $100 \mathrm{mV} / \mathrm{s}$ scan rate at $+0.6 \mathrm{~V}$ in stirred $0.1 \mathrm{M}$ sulphuric acid and $0.1 \mathrm{M} \mathrm{Na}_{2} \mathrm{SO}_{4}$ solution.

the electrode containing gold nanorods over the sphericalshaped gold nanoparticle was attributed to the different shape and different oxidation state between gold nanorod and spherical-shaped gold nanoparticle. The surface of the gold nanorod may be partially oxidized to form $\mathrm{Au}^{+}$and $\mathrm{Au}^{+3}$ during the synthesis and the oxide of the gold could be served as the mediator [22]. Figure 2 shows cyclic voltammograms of PANI in a $0.1 \mathrm{M}$ phosphate buffer solution ( $\mathrm{pH}$ 7) with and without gold nanorods. The redox peaks observed in the phosphate buffer at $\mathrm{pH} 7$ were the overlap of two redox processes for PANI under acidic conditions [17]. The reason for that gold nanorod with large specific surface area and good conductivity can provide conduction centers in the neutral solution. Therefore, the PANI-gold nanorod composite could also provide an excellent biocompatible environment for enzyme immobilization. 


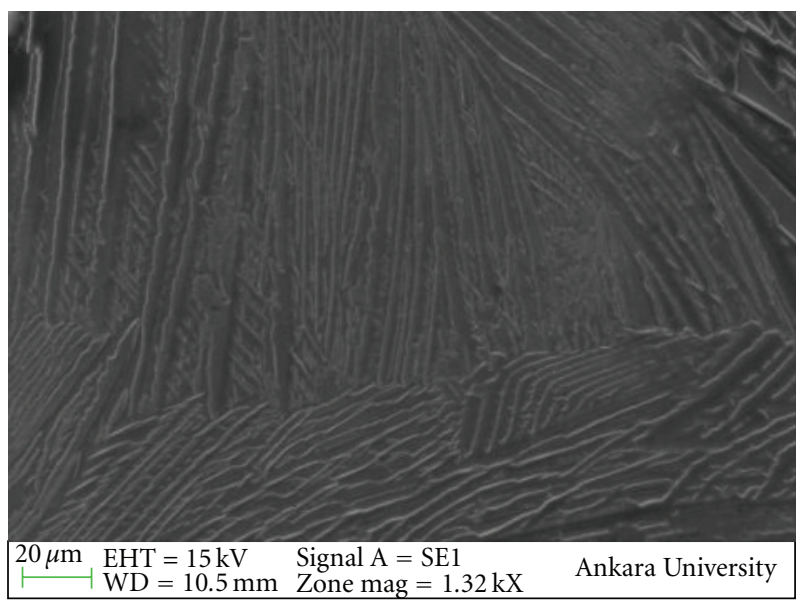

(a)

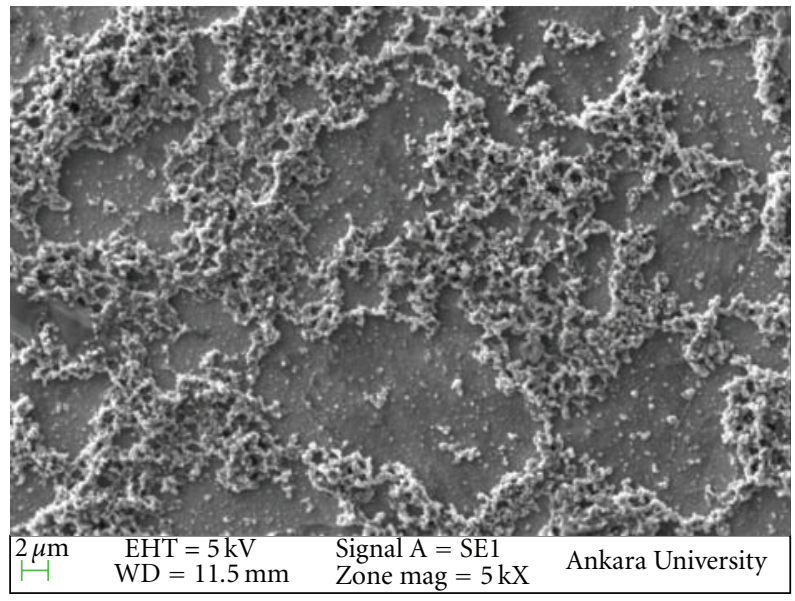

(b)

FIgure 3: SEM images of (a) PANI and (b) PANI/gold nanorod composite electrode.

The nature of the PSS-gold nanorod composite was further examined by SEM. The morphologies of PANI films obtained in the presence and in the absence of gold nanorod were found to be quite different as shown in Figure 3. While PANI prepared in the presence of gold nanorod resulted only in granular morphology, the other gave wrinkled texture as shown in Figure 3(a). This indicated that the morphology of electrochemically synthesized PANI is strongly affected by PSS-CTAB-modified gold nanorods.

\subsection{Immobilization of Enzyme on PANI/Gold Nanorod Elec-} trode. Covalent coupling of enzyme to the resulting polymer electrode was performed using glutaraldehyde which is known to be a bifunctional compound mainly used in modification of proteins. A large number of free $\mathrm{NH}_{2}$ groups are available at the end of each polyaniline chain which bind with the $\mathrm{NH}_{2}$ groups of enzymes with glutaraldehyde as a crosslinker [23]. To verify and confirm the presence of enzyme in the polymer film, SERS measurements were performed. SERS was used for illustrating the detailed structural information of the conducting polymer film. Figure 4 shows (dotted line) a typical SERS spectrum within the range of $300-2000 \mathrm{~cm}^{-1}$ of PANI film doped with PSS modified gold nanorod. A strong band at $1173 \mathrm{~cm}^{-1}$ is assigned to $\mathrm{CH}$ in-plane bending mode of quinoid and semiquinoid rings. The band at $1248 \mathrm{~cm}^{-1}$ can be assigned to $\mathrm{CN}$ stretching mode of polaronic units and in-plane deformation quinine ring. The strong band at $1497 \mathrm{~cm}^{-1}$ is assigned to $\mathrm{C}=\mathrm{N}$ stretching mode which is indicating of quinine diimine structure. Raman bands at 1592 and $1606 \mathrm{~cm}^{-1}$ are attributed to the $\mathrm{C}-\mathrm{C}$ stretching vibration of benzene rings and $\mathrm{C}-\mathrm{C}$ stretching of bipolarons, respectively [24-26]. In the SERS spectrum (Figure 4, solid line) recorded after immobilization of glucose oxidase onto the PANI film, several new bands appeared at 1710, 1377, 1075, 1030, $972,931,724$, and $643 \mathrm{~cm}^{-1}$ which are typical for glucose oxidase, indicating immobilization of glucose oxidase on the polymer surface. The strong band at $1030 \mathrm{~cm}^{-1} \mathrm{can}$

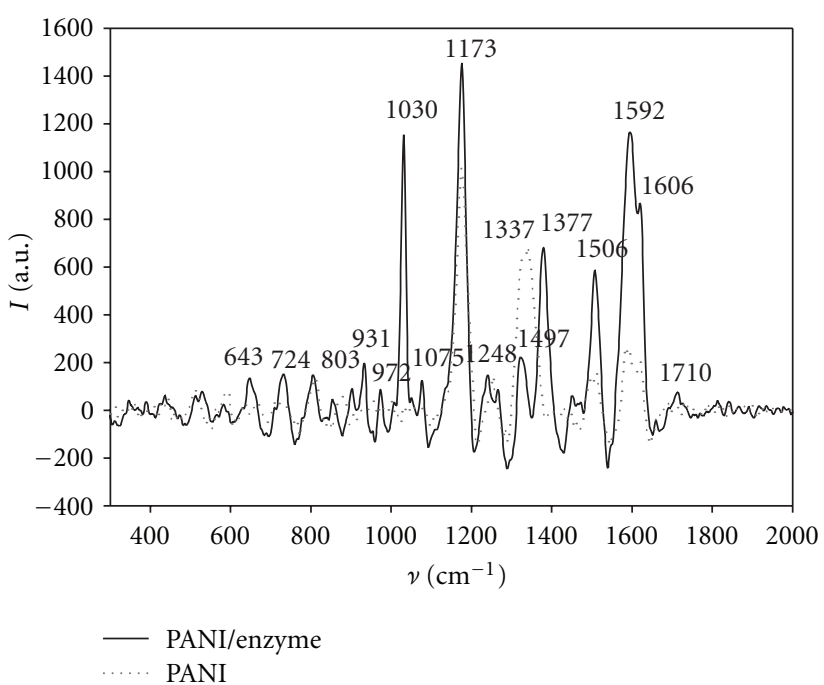

FIGURE 4: SERS spectrum within the range of $300-2000 \mathrm{~cm}^{-1}$ of PANI film doped with PSS-modified gold nanorod (dotted line) and after immobilization of glucose oxidase (solid line).

be assigned to stretching vibrations of $\mathrm{N}=\mathrm{N}$ bonds and quinone fragment [27]. The bands at 931 and $1377 \mathrm{~cm}^{-1}$ are due to the $\mathrm{C}-\mathrm{COO}$ - stretching and $\mathrm{COO}-$ symmetric stretching vibration modes, respectively $[28,29]$. The main characteristic peaks of native glucose oxidase can also be observed in the SERS spectrum as shown in Figure 5. The obtained result agrees with the reported SERS spectrum of the enzyme [30]. The similarity between the SERS spectrum of the surface-immobilized glucose oxidase and the spectrum of the native enzyme indicates that the main feature of the native structure of glucose oxidase was conserved after being immobilized on the polymer matrix.

The thickness of the film is related to the number of cycles in the potential domain selected in cyclic voltammetry. The biosensor performance for different film thicknesses was 


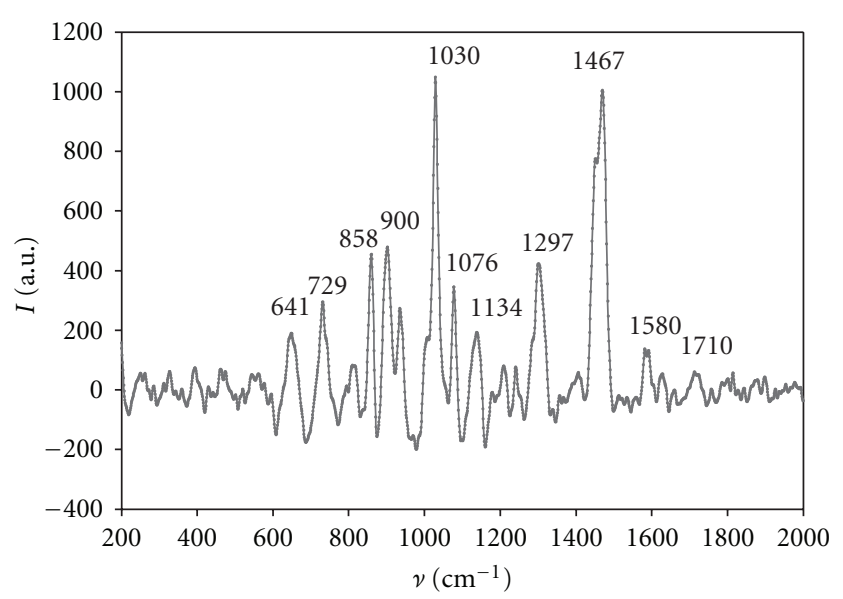

FIGURE 5: SERS spectrum of native glucose oxidase.

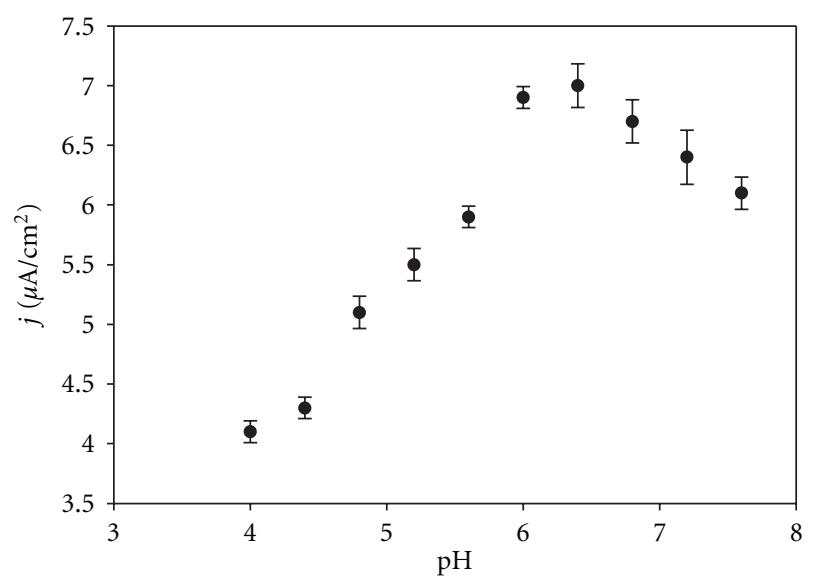

Figure 6: The effect of $\mathrm{pH}$ on the measured response of PANIgold nanorod-enzyme film by amperometric detection of $0.5 \mathrm{mM}$ glucose in $0.1 \mathrm{M}$ phosphate buffer in the range of 4.0-8.0.

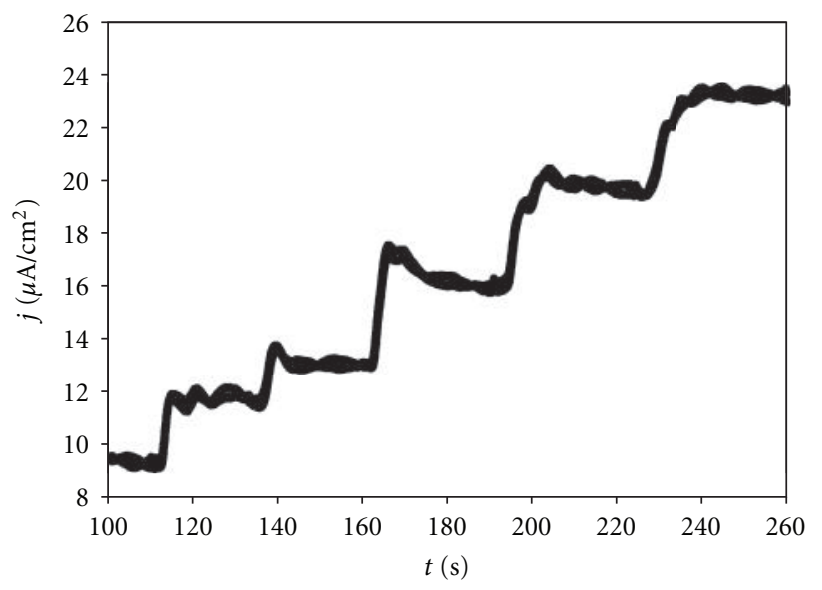

Figure 7: A typical amperometric response of the PANI-gold nanorod-enzyme biosensor after successive additions of $50 \mu \mathrm{M}$ concentrations of glucose at $+0.6 \mathrm{~V}$ versus $\mathrm{Ag} / \mathrm{AgCl}$ in stirred Phosphate buffered saline (PBS) of pH 6.4. (Glucose concentrations were prepared for the final concentrations to be 50,100, 150, 200, and $250 \mu \mathrm{M})$. evaluated by amperometric detection of $0.5 \mathrm{mM} \mathrm{H}_{2} \mathrm{O}_{2}$ at $0.6 \mathrm{~V}$ versus $\mathrm{Ag} / \mathrm{AgCl}$. By increasing the number of cycles, the biosensor response became higher with a maximum of seven cycles, and then the response decreased again. It has been found that PANI-gold nanorod-enzyme electrode with seven deposition cycles showed the desired response characteristics. The effect of $\mathrm{pH}$ was also investigated by amperometric detection of $0.5 \mathrm{mM}$ glucose in $0.1 \mathrm{M}$ phosphate buffer in the range of 4.0-8.0. As shown in Figure 6, the highest current intensity was obtained at $\mathrm{pH}$ 6.4. Each assay was repeated three times per each $\mathrm{pH}$ value. The $\mathrm{pH} 6.4$ was selected for the biosensor response.

3.3. Performance of the Biosensor. Performance of the PANIgold nanorod-enzyme biosensor was evaluated at room temperature. Figure 7 displays a typical amperometric res-ponse of the PANI-gold nanorod-enzyme biosensor upon successive additions of $50 \mu \mathrm{M}$ concentrations of glucose at $+0.6 \mathrm{~V}$ versus $\mathrm{Ag} / \mathrm{AgCl}$ in phosphate buffer of $\mathrm{pH}$ 6.4. So glucose concentrations were prepared for the final concentrations to be $50,100,150,200$, and $250 \mu \mathrm{M}$. With successively increasing the concentration of glucose, a well-defined increase in the current was observed.

The biosensor also shows rapid response to the change of glucose concentration. The response time for the electrode is less than three seconds under optimum conditions. A linear relationship is obtained in the concentration range from $17 \mu \mathrm{M}$ to $1 \mathrm{mM}$ with a sensitivity of $13.8 \mu \mathrm{A} \cdot \mathrm{mM}^{-1} \cdot \mathrm{cm}^{-2}$ and a limit of detection (LOD) of $5.8 \mu \mathrm{M}$. Reproducibility of the biosensor was evaluated from the response for $10 \mathrm{mM}$ glucose at six different biosensors and an RSD value of $2.4 \%$ was observed. The enzyme electrode was found to be stable over one week when it was stored at $5^{\circ} \mathrm{C}$ as dry. The apparent Michaelis-Menten constant $K_{\mathrm{M}}$ indicates the enzyme-substrate kinetics. It was used for evaluating the biological activity of the immobilized enzyme. $K_{\mathrm{M}}$ was calculated as $1 \mathrm{mM}$ according to the Lineweaver-Burk equation which indicated maximal catalytic activity of the enzyme at low substrate concentrations.

The analytical performance of PANI/gold nanorod/Glucose Oxidase (GOD) enzyme electrode was also compared with PANI/GOD electrode; the results are given in Table 1. As it can be inferred from this table, an amperometric signal in the presence of gold nanorods was higher by three orders of magnitude as compared with signals obtained in the absence of the particles. This difference can be related to the different diffusion properties of PANI/gold nanorod/GOD electrode.

In a real matrix, some electroactive species such as ascorbic acid, and uric acid may be involved in the electrochemical reaction and may therefore affect the biosensor response. The main contribution of the presence of a carboxylate group in the polymer structure is the exclusion of these matrix effects. The effect of these interfering substances was tested at their normal physiological concentrations. The addition of $0.05 \mathrm{mM}$ ascorbic acid and $0.2 \mathrm{mM}$ uric acid exhibited no effect on the response of the PANI-gold nanorod-enzyme biosensor as shown in Figure 8. 
TABLE 1: Comparison of analytical performance of PANI and PANI-gold nanorod-enzyme film.

\begin{tabular}{lcccc}
\hline & LOD $^{\mathrm{a}}(\mathrm{mol} / \mathrm{L})$ & $\mathrm{LOQ}^{\mathrm{b}}(\mathrm{mol} / \mathrm{L})$ & Linear range $(\mathrm{mmol} / \mathrm{L})$ & Michaelis-Menten constant $(\mathrm{mmol} / \mathrm{L})$ \\
\hline PANI/GOD & $1.08 \times 10^{-3}$ & $3.24 \times 10^{-3}$ & $3.24-12$ & 4.62 \\
PANI/Au/GOD & $5.86 \times 10^{-6}$ & $0.0176 \times 10^{-3}$ & $0.0176-1$ & 1 \\
\hline
\end{tabular}

${ }^{\mathrm{a}}:$ Limit of detection, ${ }^{\mathrm{b}}:$ Limit of quantification.

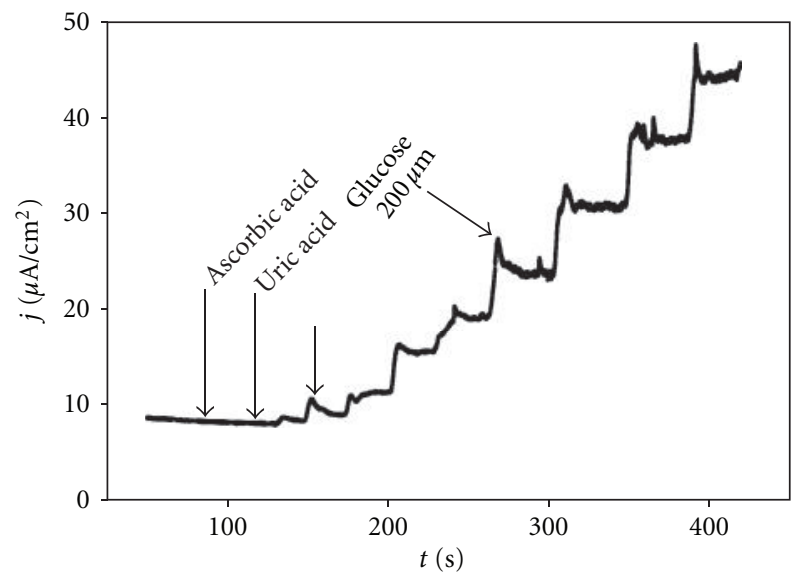

Figure 8: A typical amperometric response of the PANI-gold nanorod-enzyme biosensor after addition of $0.05 \mathrm{mM}$ ascorbic acid, $0.2 \mathrm{mM}$ uric acid, and glucose at $+0.6 \mathrm{~V}$ versus $\mathrm{Ag} / \mathrm{AgCl}$ in stirred PBS of $\mathrm{pH} 6.4$.

When the developed method was compared with other works, there are some advantages. For instance, a study that is based on SPR system consisted of polypyrrole and GOx on sensor chip could detect range of $1-100 \mu \mathrm{M}$ glucose concentration. Tian et al. used two steps for this detection procedure as electrochemical technique for modifying chip sensor and optical technique for detecting glucose. On the other hand, our previous study showed that glucose sensor, which developed with 3-aminophenylboronic acid, has had lack ability for six times than ability of fructose, and SPR calibration was linear in the concentration range of $10-120 \mathrm{mM}$. Here, electrochemically organized glucose sensor prevails to SPR one in terms of preparation and detection limit. Also, Chu et al. designed a biocompatible glucose sensor. This sensor linearly corresponded to glucose concentration over a range of $0.05-4 \mathrm{mM}$. Our sensor has an advantage and a disadvantage when detection limit and biocompatible property thought. For suitably biocompatible sensor, some application must be required. As for the time required for detection, our sensor is quite rapid according to SPR, but almost similar to other sensors which work with electrochemical and optical techniques [31-33].

The developed sensor is fairly cheap because the chemicals were low amounts for fabrication PANI-gold nanorod electrode.

\section{Conclusion}

It can be concluded that PANI-gold nanorod is a suitable candidate for enzyme immobilization and detection of biological compounds. The SERS spectrum of the surfaceimmobilized glucose oxidase and the spectrum of the native enzyme indicate that the main feature of the native structure of glucose oxidase was conserved after being immobilized on the polymer matrix. Advantages of this biosensor over the previously developed sensors include ease of preparation and rapid response time. An amperometric signal in the presence of gold nanorods was higher by three orders of magnitude as compared with signals obtained in the absence of the particles. Also, the influence of some potential interference such as ascorbic acid and uric acid on the measured current value was not observed. The PANI-gold nanorod may offer a broad potential range for electroanalytical applications.

\section{Acknowledgment}

This research was supported by Gazi University, Research Fund through Grants no. 02/2007-06 and no. 02/2005-20.

\section{References}

[1] N. S. Oliver, C. Toumazou, A. E.G. Cass, and D. G. Johnston, "Glucose sensors: a review of current and emerging technology," Diabetic Medicine, vol. 26, no. 3, pp. 197-210, 2009.

[2] T. W. Siegel, S. R. Smith, C. A. Ellery, J. R. Williamson, and P. J. Oates, "An enzymatic fluorometric assay for fructose," Analytical Biochemistry, vol. 280, no. 2, pp. 329-331, 2000.

[3] L. Cao, J. Ye, L. Tong, and B. Tang, "A new route to the considerable enhancement of glucose oxidase (GOx) activity: the simple assembly of a complex from CdTe quantum dots and GOx, and its glucose sensing," Chemistry: A European Journal, vol. 14, no. 31, pp. 9633-9640, 2008.

[4] H. Mugurunia, Y. Kase, N. Murata, and K. Matsumura, "Adsorption of glucose oxidase onto plasma-polymerized film characterized by atomic force microscopy, quartz crystal microbalance, and electrochemical measurement," Journal of Physical Chemistry B, vol. 110, no. 51, pp. 26033-26039, 2006.

[5] M. Gerard, A. Chaubey, and B. D. Malhotra, "Application of conducting polymers to biosensors," Biosensors and Bioelectronics, vol. 17, no. 5, pp. 345-359, 2002.

[6] S. Cosnier, "Affinity biosensors based on electropolymerized films," Electroanalysis, vol. 17, no. 19, pp. 1701-1715, 2005.

[7] P. Santhosh, A. Gopalan, and K.-P. Lee, "Gold nanoparticles dispersed polyaniline grafted multiwall carbon nanotubes as newer electrocatalysts: preparation and performances for methanol oxidation," Journal of Catalysis, vol. 238, no. 1, pp. 177-185, 2006.

[8] C. A. Foss Jr., M. J. Tierney, and C. R. Martin, "Template synthesis of infrared-transparent metal microcylinders: comparison of optical properties with the predictions of effective medium theory," Journal of Physical Chemistry, vol. 96, no. 22, pp. 9001-9007, 1992. 
[9] Z. Wang, J. Yuan, M. Li et al., "Electropolymerization and catalysis of well-dispersed polyaniline/carbon nanotube/gold composite," Journal of Electroanalytical Chemistry, vol. 599, no. 1, pp. 121-126, 2007.

[10] Md. A. Rahman, P. Kumar, D. S. Park, and Y. Shim, "Electrochemical sensors based on organic conjugated polymers," Sensors, vol. 8, no. 1, pp. 118-141, 2008.

[11] A. Morrin, O. Ngamna, A. J. Killard, S. E. Moulton, M. R. Smyth, and G. G. Wallace, "An amperometric enzyme biosensor fabricated from polyailine nanoparticles," Electroanalysis, vol. 17, no. 5-6, pp. 423-430, 2005.

[12] S. Virji, J. Huang, R. B. Kaner, and B. H. Weiller, "Polyaniline nanofiber gas sensors: examination of response mechanisms," Nano Letters, vol. 4, no. 3, pp. 491-496, 2004.

[13] M. Zhang, A. Yamaguchi, K. Morita, and N. Teramae, "Electrochemical synthesis of Au/polyaniline-poly(4-styrenesulfonate) hybrid nanoarray for sensitive biosensor design," Electrochemistry Communications, vol. 10, no. 7, pp. 10901093, 2008.

[14] S. I. Cho, D. H. Choi, S. H. Kim, and S. B. Lee, "Electrochemical synthesis and fast electrochromics of poly(3,4-ethylenedioxythiophene) nanotubes in flexible substrate," Chemistry of Materials, vol. 17, no. 18, pp. 4564-4566, 2005.

[15] T. K. Sarma, D. Chowdhury, A. Paul, and A. Chattopadhyay, "Synthesis of Au nanoparticle-conductive polyaniline composite using $\mathrm{H}_{2} \mathrm{O}_{2}$ as oxidising as well as reducing agent," Chemical Communications, vol. 10, pp. 1048-1049, 2002.

[16] E. Granot, E. Katz, B. Basnar, and I. Willner, "Enhanced bioelectrocatalysis using Au-nanoparticle/polyaniline hybrid systems in thin films and microstructured rods assembled on electrodes," Chemistry of Materials, vol. 17, no. 18, pp. 46004609, 2005.

[17] Y. Liu, X. Feng, J. Shen, J. J. Zhu, and W. Hou, "Fabrication of a novel glucose biosensor based on a highly electroactive polystyrene/polyaniline/Au nanocomposite," Journal of Physical Chemistry B, vol. 112, no. 30, pp. 9237-9242, 2008.

[18] Y. Xian, Y. Hu, F. Liu, Y. Xian, H. Wang, and L. Jin, "Glucose biosensor based on Au nanoparticles-conductive polyaniline nanocomposite," Biosensors and Bioelectronics, vol. 21, no. 10, pp. 1996-2000, 2006.

[19] X. Ren, D. Chen, X. Meng, F. Tang, A. Du, and L. Zhang, "Amperometric glucose biosensor based on a gold nanorods/cellulose acetate composite film as immobilization matrix," Colloids and Surfaces B, vol. 72, no. 2, pp. 188-192, 2009.

[20] B. Nikoobakht and M. A. El-Sayed, "Preparation and growth mechanism of gold nanorods (NRs) using seed-mediated growth method," Chemistry of Materials, vol. 15, no. 10, pp. 1957-1962, 2003.

[21] C. J. Orendorff, A. Gole, T. K. Sau, and C. J. Murphy, "Surfaceenhanced Raman spectroscopy of self-assembled monolayers: sandwich architecture and nanoparticle shape dependence," Analytical Chemistry, vol. 77, no. 10, pp. 3261-3266, 2005.

[22] Z. Jia, J. Liu, and Y. Shen, "Fabrication of a templatesynthesized gold nanorod-modified electrode for the detection of dopamine in the presence of ascorbic acid," Electrochemistry Communications, vol. 9, no. 12, pp. 2739-2743, 2007.

[23] S. Singh, P. R. Solanki, M. K. Pandey, and B. D. Malhotra, "Covalent immobilization of cholesterol esterase and cholesterol oxidase on polyaniline films for application to cholesterol biosensor," Analytica Chimica Acta, vol. 568, no. 1-2, pp. 126132, 2006.

[24] L. S. Jiao, Z. Wang, L. Niu et al., "In situ electrochemical SERS studies on electrodeposition of aniline on 4-ATP/Au surface,"
Journal of Solid State Electrochemistry, vol. 10, no. 11, pp. 886893, 2006.

[25] M. Baibarac, L. Mihut, G. Louarn et al., "Interfacial chemical effect evidenced on SERS spectra of polyaniline thin films deposited on rough metallic supports," Journal of Raman Spectroscopy, vol. 30, no. 12, pp. 1105-1113, 1999.

[26] C. Liu, J. Zhang, G. Shi, and F. Chen, "Doping level change of polyaniline film during its electrochemical growth process," Journal of Applied Polymer Science, vol. 92, no. 1, pp. 171-177, 2004.

[27] M. Mazur, P. Krysiński, A. Michota-Kamińska, J. Bukowska, J. Rogalski, and G. J. Blanchard, "Immobilization of laccase on gold, silver and indium tin oxide by zirconium-phosphonatecarboxylate (ZPC) coordination chemistry," Bioelectrochemistry, vol. 71, no. 1, pp. 15-22, 2007.

[28] K. S. Kyu, K. M. Soo, and S. Won, "Surface-enhanced raman scattering (SERS) of aromatic amino acids and their glycyl dipeptides in silver sol," Journal of Raman Spectroscopy, vol. 18, pp. 171-175, 1987.

[29] A. Kudelski, "Raman study on the structure of 3-mercaptopropionic acid monolayers on silver," Surface Science, vol. 502503, pp. 219-223, 2002.

[30] R. E. Holt and T. M. Cotton, "Free flavin interference in surface enhanced resonance raman spectroscopy of glucose oxidase ," Journal of the American Chemical Society, vol. 109, pp. 1841-1845, 1987.

[31] Ö. Torun, F. C. Dudak, D. Baş, U. Tamer, and İ. H. Boyacı, "Thermodynamic analysis of the interaction between 3aminophenylboronic acid and monosaccharides for development of biosensor," Sensors and Actuators B, vol. 140, no. 2, pp. 597-602, 2009.

[32] L. Tian, J. Qiu, Y.-C. Zhou, and S.-G. Sun, "Application of polypyrrole/GOx film to glucose biosensor based on electrochemical-surface plasmon resonance technique," Microchimica Acta, vol. 169, no. 3, pp. 269-275, 2010.

[33] Y. Hiranuma, H. Hiramatsu, M. X. Chu et al., "Flexible glucose sensor with biocompatible polymer substrate," Journal of Advanced Science, vol. 22, pp. 9-10, 2010. 


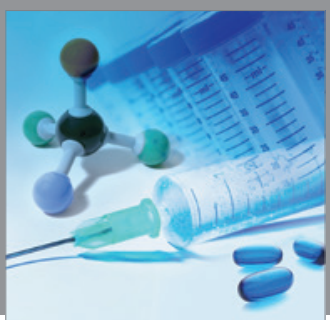

International Journal of

Medicinal Chemistry

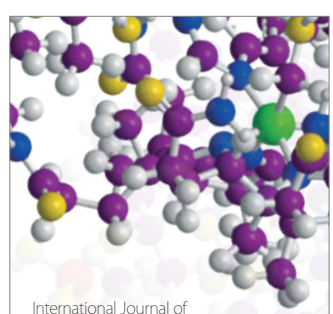

Carbohydrate Chemistry

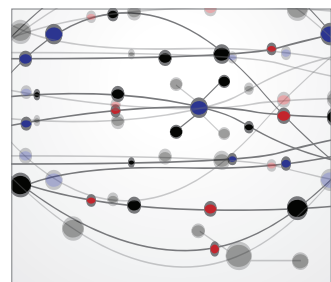

The Scientific World Journal
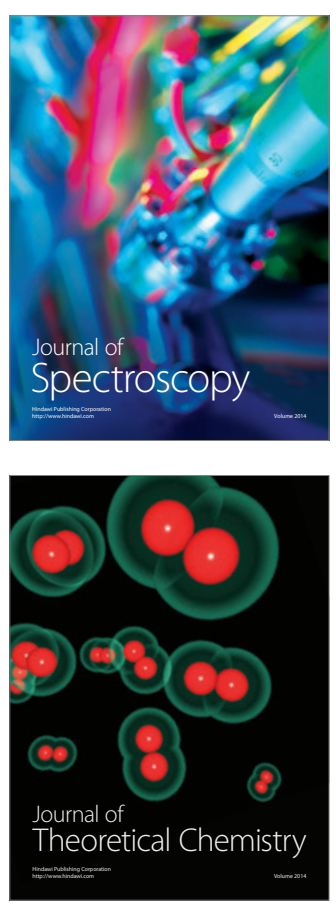
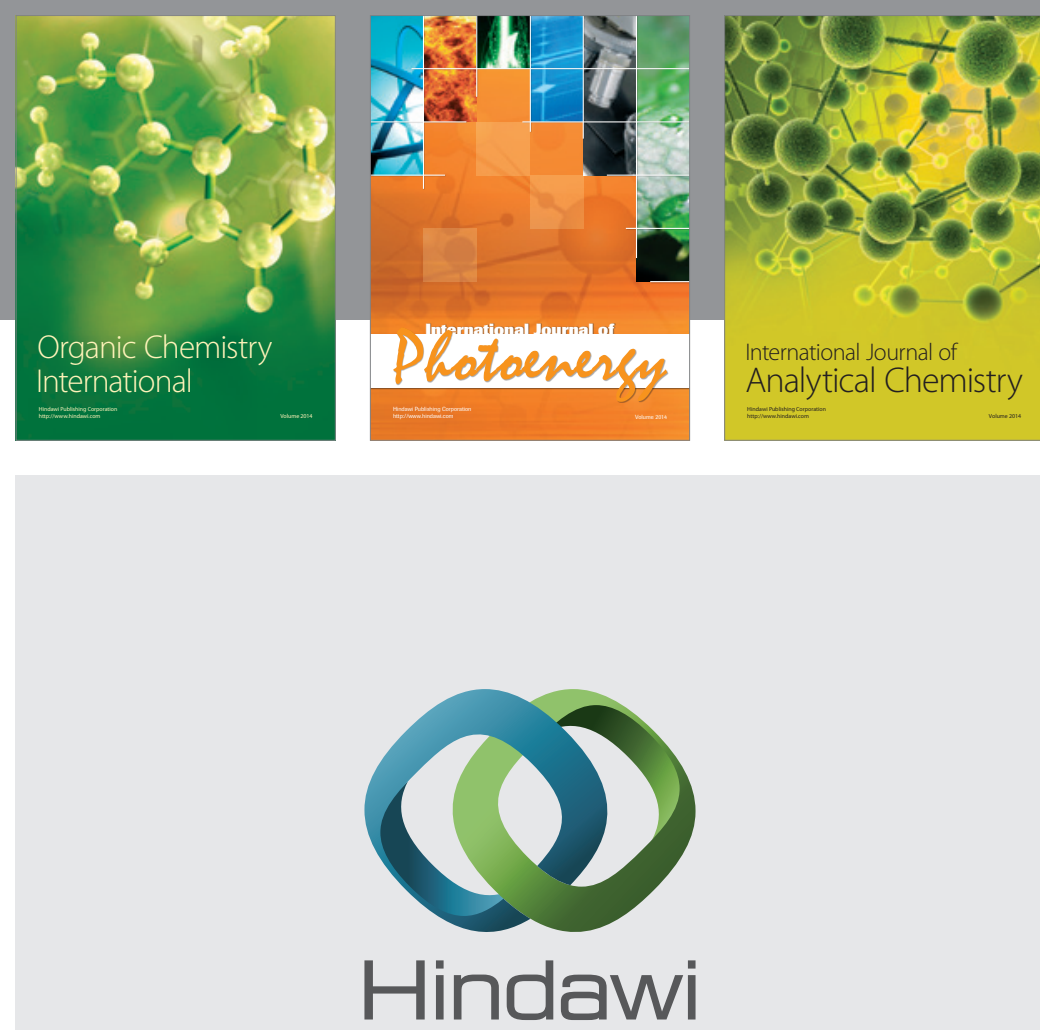

Submit your manuscripts at

http://www.hindawi.com
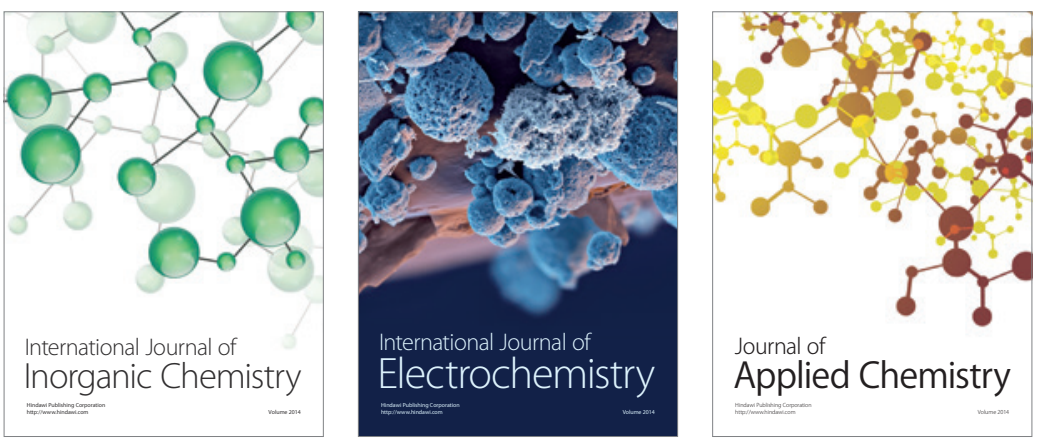

Journal of

Applied Chemistry
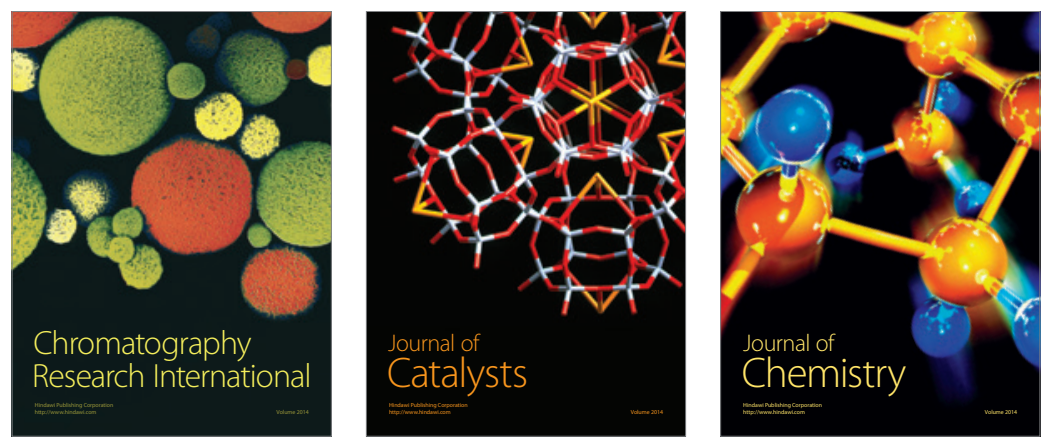
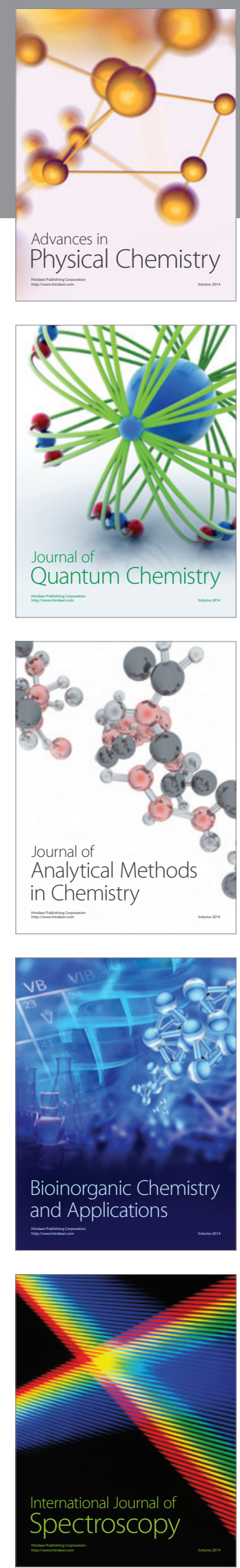